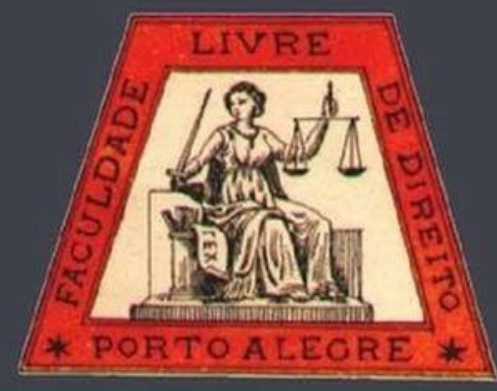

\title{
Liberdade de expressão e ponderação de valores: tutela da dignidade da pessoa humana versus hate speech
}

Freedom of expression and balancing values: protection of human dignity versus hate speech

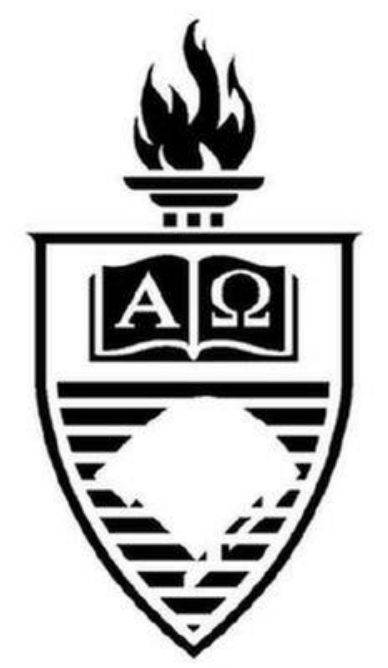

Jaianny Saionara Macena de Araújo

Pontifícia Universidade Católica de Minas Gerais

\section{Magno Gurgel Saraiva \\ Universidade Nova de Lisboa}

Adriano Marteleto Godinho

Universidade Federal da Paraíba

\section{UFRGS}



Liberdade de expressão e ponderação de valores: tutela da dignidade da pessoa humana versus
hate speech

\author{
Freedom of expression and balancing values: protection of human dignity versus hate speech
}

Jaianny Saionara Macena de Araújo*

Magno Gurgel Saraiva**

\author{
Adriano Marteleto Godinho ${ }^{* * *}$
}

\title{
REFERÊNCIA
}

ARAÚJO, Jaianny Saionara Macena de; SARAIVA, Magno Gurgel; GODINHO, Adriano Marteleto. Liberdade de expressão e ponderação de valores: tutela da dignidade da pessoa humana versus hate speech. Revista da Faculdade de Direito da UFRGS, Porto Alegre, n. 40, p. 101-115, ago. 2019.

\section{RESUMO}

Este trabalho tem como objetivo desenvolver a discussão sobre a liberdade de expressão e seu conflito com o discurso de ódio no ordenamento jurídico brasileiro. Deste modo, expõe-se o entendimento e a dimensão do discurso de ódio, assim como sua resolução diante de casos concretos e a reparação civil pelos danos oriundos. Neste contexto, a Ciência Jurídica não pode ser indiferente ao conteúdo dessas normas, tampouco à sua capacidade de adequação aos problemas sociais. O exercício das liberdades civis, sob este prisma, tem muito a ser enriquecido, à medida que se expande a compreensão - antes eminentemente limitada à esfera normativa privada - e passa a tratar da proteção e garantia de direitos com uma preocupação finalística que deve cuidar evidentemente dos direitos humanos, de sua validade fundada tanto na lei, quanto na Constituição, e de sua real eficácia em favor da dignidade humana.

\section{PALAVRAS-CHAVE}

Direitos Humanos. Direitos Fundamentais. Discurso de ódio. Dignidade da pessoa humana. Liberdade de expressão.

\section{SUMÁRIO}

Introdução. 1. A dignidade da pessoa humana como atributo nuclear do ordenamento jurídico. 2. Ponderação de interesses como meio de tutela contra o hate speech. 3. O caso da jornalista Maria Júlia Coutinho. 4. O problema das redes sociais enquanto difusoras do hate speech. Conclusão. Referências.

\footnotetext{
* Advogada - OAB/PB. Pós-graduanda em Direito Civil pela Pontifícia Universidade Católica de Minas Gerais. Bacharela em Ciências Jurídicas e Sociais pela Universidade Federal da Paraíba.

*** Mestrando em Direito Internacional pela Universidade Nova de Lisboa. Bacharel em Ciências Jurídicas e Sociais pela Universidade Federal da Paraíba.

**** Professor da Universidade Federal da Paraíba. Doutor em Ciências Jurídicas pela Universidade de Lisboa e Mestre em Direito Civil pela Universidade Federal de Minas Gerais. Advogado.
}

\begin{abstract}
This paper aims to develop the discussion about freedom system. Thus, it shows the concept and dimension of hate speech, as well as the resolution in specific cases and the civil liability for damages. In this sense, Law can't be adequation capacity towards the social problems. The exercise of civil liberties, based on this conception, has a lot to be enriched, as far as it expands the understanding previously limited eminently to the private normative rights with a concern that obviously has to take care of human rights, as well as its real effectiveness in favor of
\end{abstract}

Human rights. Fundamental rights. Hate speech. Human dignity. Freedom of speech. 


\section{INTRODUÇÃO}

Com o passar do tempo, percebe-se o gradativo avanço tecnológico e, com as constantes inovações dele emergentes, emerge a dependência da sociedade em relação aos mais modernos meios midiáticos. Acerca do assunto, Pierre Lévy aduz:

Durante uma entrevista nos anos 50, Albert Einstein declarou que três grandes bombas haviam explodido durante o século XX: a bomba demográfica, a bomba nuclear e a bomba das telecomunicações. Aquilo que Einstein chamou de bomba das telecomunicações foi chamado, por meu amigo Roy Ascott (um dos pioneiros e principais teóricos da arte em rede), de "segundo dilúvio", o das informações. ${ }^{1}$

Einstein não estava equivocado acerca da "bomba das telecomunicações", visto que a população vive constantemente cercada de informações. Ilustrativamente, mencionam-se páginas de internet e programas televisivos que trazem inúmeras notícias, em tempo real.

De acordo com reportagem publicada pelo IBOPE em julho de 2015, um cidadão brasileiro passa em média 5,3 horas diariamente conectado à internet. Além disso, em pesquisa encomendada pela Secretaria de Comunicação Social (SECOM), a população brasileira assiste à televisão, aproximadamente, $4 \mathrm{~h} 31 \mathrm{~min}$ por dia entre segunda-feira a sexta-feira e $4 \mathrm{~h} 14 \mathrm{~min}$ aos sábados e domingos. Por sua vez, durante a semana, as pessoas usufruem do rádio cerca de $3 \mathrm{~h} 42 \mathrm{~min}$ por dia e $2 \mathrm{~h} 33 \mathrm{~min}$ nos fins de semana.

A temática "Direito e Mídia" é oriunda das repercussões sobre divergentes entendimentos envolvendo questões inseridas em "áreas de conflito" entre o Direito e a Comunicação. Pode-se apontar enquanto desdobramentos do tópico em questão as

${ }^{1}$ LÉVY, Pierre. Cibercultura. Tradução de Carlos Irineu Costa. São Paulo: Ed. 34, 1999, p.2. relações de poder que a mídia exerce no âmbito jurídico, com especial acento sobre o confronto entre a liberdade de expressão e o crescente discurso de ódio.

Diante da atual conjuntura, impõe-se ressaltar que tanto a liberdade de expressão quanto a liberdade de imprensa são asseguradas pela Constituição Federal de 1988, nos artigos $5^{\circ}$, inciso IX e no art. 220, respectivamente. Entretanto, por vezes, sua prática não se manifesta regular e licitamente pelos meios de comunicação. Através da propagação da internet, aumentaram os acontecimentos em que aquelas liberdades foram excedidas, ocasionando casos que incentivam o hate speech e propiciam o crescimento da discriminação a diversos grupos vulneráveis.

O propósito destas linhas consiste, pois, na investigação sobre o significado do discurso de ódio e os mecanismos jurídicos de sua contenção, com o intuito de propiciar o estabelecimento de limites a liberdade de expressão e a ampla tutela do eminente princípio da dignidade da pessoa humana.

\section{A DIGNIDADE DA PESSOA HUMANA COMO ATRIBUTO NUCLEAR DO ORDENAMENTO JURÍDICO}

Em diversas cartas político-jurídicas, espalhadas pelo mundo, convencionou-se inserir a dignidade da pessoa humana como elemento nuclear. Enunciá-la como princípio fundamental de um Estado não é pouco, nem se trata de mera retórica: proclamar a primazia da dignidade dos homens significa colocá-los como início e fim do Direito e, ao fim e ao cabo, revisitar a história e rejeitar os efeitos nefastos das diversas ocorrências - especialmente as que se verificaram nas duas grandes guerras mundiais em que seres humanos se viram vilipendiados em seus direitos mais basilares. Mais do que isso, firmar uma ordem jurídica ancorada no 
primado da dignidade da pessoa humana implica reconhecer que ela é atributo de um e de todos. Noutros termos, "a simples circunstância de ser um indivíduo humano, enquanto realidade biológica possuidora de um genoma humano, envolve que possua dignidade". ${ }^{2}$

O princípio da dignidade da pessoa humana tem o condão de inserir o ser humano no centro da ordem jurídica. Em torno deste preceito gravitam os demais direitos, o que se extrai da própria posição que a matéria ocupa, particularmente, na Constituição brasileira: ao elencar o princípio entre os fundamentos da República, a ordem constitucional faz com que o elenco de direitos e garantias que se seguem consista em verdadeiro corolário da dignidade da pessoa humana, que, por isso, se estabelece como valor fundante de todo o ordenamento. Disto se deduz que a dignidade da pessoa humana implicará o irrecusável reconhecimento da prioridade de cada indivíduo, de natureza e qualidade irrepetível, de sua autonomia ética enquanto ser singular e concreto, em favor de quem se prostram os poderes públicos e as políticas estatais, e nunca o oposto. ${ }^{3}$ Uma vez incorporada ao texto da Constituição da República como um dos seus fundamentos, a dignidade da pessoa humana passa a valer como ratio de todo o sistema normativo. Trata-se de um preceito cujo respeito se torna o mais relevante critério de valoração da legitimidade da atuação do Estado, vinculando-o ao dever de prover, em prol das pessoas, meios de prevenção e proteção da dignidade que lhes é imanente contra todo tipo de intervenção, proveniente de outros particulares ou de quaisquer entidades,

\footnotetext{
${ }^{2}$ OTERO, Paulo. Instituições políticas e constitucionais, v. I. Coimbra: Almedina, 2007, p. 546-547.

3 DÍEZ-PICAZO, Luis Maria. Sistema de derechos fundamentales. Madrid: Thomson-Civitas, 2003, p. 64-65.
}

que de algum modo sejam suscetíveis de afetála. ${ }^{4}$

Veja-se, portanto, o papel que desempenha a dignidade da pessoa humana em diversas ordens jurídicas, nomeadamente na brasileira: ela não integra o rol dos direitos fundamentais, sendo antes alicerce $\mathrm{e}$ fundamento deles. A dignidade da pessoa humana atua num sentido prioritário, não se qualificando como um autêntico direito, mas como uma qualidade intrínseca e como base de sustentação de todos os direitos. Trata-se de um valor, cujo menoscabo conduziria à depreciação da própria condição humana de cada pessoa. ${ }^{5}$

Apesar de sua indiscutível relevância, é notória a dificuldade de se estabelecer os contornos que permitam definir o sentido da dignidade da pessoa humana: no mais das vezes, diz-se que só se consegue apreender tal significação pela "via negativa", isto é, a partir das suas violações. Isto não obstante, Roberto Andorno ensaia sua definição, ou, segundo diz, uma "aproximação conceitual", ao afirmar que a dignidade humana se refere

ao valor único e incondicional que tem a existência de todo ser humano, independentemente de qualquer 'qualidade acessória' que pudesse corresponder por razões de idade, estado de saúde física ou mental, origem étnica, sexo, condição social ou econômica ou religião. É sua condição humana como tal o que gera um dever de respeito para com o indivíduo, sem que seja exigível nenhum outro requisito adicional. ${ }^{6}$

\footnotetext{
${ }^{4}$ NOVAIS, Jorge Reis. Os princípios constitucionais estruturantes da República Portuguesa. Coimbra: Ed. Coimbra, 2004, p. 52.

5 ORTIZ-ORTIZ, Rafael. La dignidad humana y el desarrollo de la personalidad como premisa axiológica del constitucionalismo venezolano. Revista de la Fundación Procuradoria, Caracas, a. 11, n. 14 (1996), p. 107.

6 ANDORNO, Roberto. "Liberdade" $e$ "dignidade" da pessoa: dois paradigmas opostos ou complementares na bioética? In: MARTINS-COSTA, Judith; MÖLLER, Letícia Ludwig (Org.). Bioética e responsabilidade. Rio de Janeiro: Forense, 2009, p. 80-82.
} 
Malgrado a vaguidão própria de conceitos jurídicos indeterminados - como o que está em apreço - e que é típica da fluidez de fenômenos jurídicos que assumem um caráter de universalidade, extrai-se, de Ingo Sarlet, um conceito composto por elementos suficientemente precisos:

Temos por dignidade da pessoa humana a qualidade intrínseca e distintiva de cada ser humano que o faz merecedor do mesmo respeito e consideração por parte do Estado e da comunidade, implicando, neste sentido, um complexo de direitos e deveres fundamentais que asseguram a pessoa tanto contra todo e qualquer ato de cunho degradante e desumano, como venham a lhe garantir as condições existenciais mínimas para uma vida saudável, além de propiciar e promover sua participação ativa e co-responsável nos destinos da própria existência e da vida em comunhão com os demais seres humanos. ${ }^{7}$

O princípio da dignidade da pessoa humana deve, pois, ser entendido em todas as suas dimensões: como limitações ao poder, no sentido de se estabelecer um campo de proteção pessoal contra todo tipo de intervenção estatal abusiva, "impondo-se frente a totalitarismos e contra experiências de aniquilamento existencial do ser humano, tais como escravidão, nazismo, genocídios étnicos, entre outros"; ${ }^{8}$ a seguir, como reconhecimento da igualdade entre os homens, porque a dignidade, valor universal, é idêntica e a todos atribuída na mesma proporção; como respeito à liberdade e, mais particularmente à autonomia privada, permitindo-se à pessoa a busca da sua realização; e, por fim, como um impedimento à degradação da pessoa, que jamais pode ser reduzida à condição de coisa - o ser humano é

\footnotetext{
${ }^{7}$ SARLET, Ingo Wolfgang. Dignidade da pessoa humana e direitos fundamentais na Constituição Federal de 1988. Porto Alegre: Livraria do Advogado, 2008, p. 63.

${ }^{8}$ CANOTILHO, José Joaquim Gomes; MOREIRA, Vital. Constituição da República Portuguesa anotada. 4. ed. Coimbra: Ed. Coimbra, 2007, p. 198.
}

sujeito e é fim, nunca objeto nem meio para a satisfação dos fins alheios.

Das dimensões que emanam do primado da dignidade da pessoa humana, derivam diversas projeções, também albergadas pela Constituição da República brasileira, e que têm por objeto a proteção e a promoção da pessoa e dos seus valores mais caros: a previsão de que ninguém será submetido a tortura nem a tratamento desumano ou degradante (art. $5^{\circ}$, III); a inviolabilidade da liberdade de consciência e de crença (art. 5o, VI); a inviolabilidade da intimidade, da vida privada, da honra e da imagem das pessoas (art. $5^{\circ}, \mathrm{X}$ ); a liberdade de locomoção (art. $5^{\circ}, \mathrm{XV}$ ), entre diversas outras.

De todo modo, ainda que seja possível apontar as dimensões para as quais o princípio da dignidade da pessoa humana se projeta, a sua própria natureza de "cláusula aberta" reclama uma aplicabilidade algo casuística. Há balizas que permitem identificar o sentido de dignidade previsto por diversas Constituições, entre elas a brasileira; mas é diante das circunstâncias de cada caso que se constrói definitivamente o conteúdo do princípio, dirigido à pessoa real e concreta, ${ }^{9}$ não a um ser ideal e abstratamente considerado.

Digna de nota é a constatação de duas projeções da dignidade da pessoa humana, que, à partida, se revelam antagônicas. Por um lado, a dignidade implica autonomia, liberdade para agir e fazer as próprias escolhas existenciais; por outro lado, a dignidade impõe também a proteção de um núcleo mínimo de existência humana, contra o qual ninguém - nem mesmo o próprio titular desta dignidade, caso queira poderá atentar. Paradoxalmente, a ideia de dignidade desempenha a função de atribuir liberdade e, ao mesmo tempo, de restringir esta mesma liberdade, sobretudo quando tender à

\footnotetext{
${ }^{9}$ MIRANDA, Jorge. A dignidade da pessoa humana e a unidade valorativa do sistema de direitos fundamentais. In: Estudos em homenagem ao Prof. Doutor Martim de Albuquerque, v. I. Coimbra: Ed. Coimbra, 2010, p. 938.
} 
consumação de violações de tal sorte graves que possam comprometer a própria dignidade e a personalidade de um indivíduo.

De todo modo, resguardar o núcleo duro da dignidade da pessoa humana é um imperativo que se impõe categoricamente pelo comando constitucional. Qualquer ato que represente violação à dignidade de qualquer pessoa significará um atentado à dignidade humana como um todo. É crucial que se estabeleça, portanto, esta baliza: todo e qualquer discurso, mesmo que ancorado na permissão constitucional da livre expressão, encontra, como barreira fundamental, o respeito à eminente dignidade humana.

\section{PONDERAÇÃO DE INTERESSES COMO MEIO DE TUTELA CONTRA O HATE SPEECH}

A liberdade de expressão é valor essencial em qualquer regime constitucional que se pretenda democrático. Apesar de este direito fundamental ser amplamente discutido na doutrina nacional, especialmente pelo contexto pós-ditatorial, em poucos trabalhos brasileiros se acha o tema com enfoque no hate speech. Tal situação, provavelmente, decorre da incredulidade dos doutrinadores quanto ao resguardo desse tipo de discurso dentro do ordenamento jurídico da Carta Magna de 1988.

Portanto, parte-se dos conceitos presentes no Direito Constitucional e, principalmente, no Direito Civil-Constitucional, a fim de que se identifique a denominação mais próxima do que seria o hate speech.

Conforme Travassos, hate speech é "um instituto jurídico difundido em alguns países por meio do qual se permite o exercício da liberdade de expressão de forma ilimitada e se abre a toda e qualquer pessoa" ${ }^{10}$. Assim sendo, o hate speech embasa as mais variadas maneiras de se manifestar discriminatoriamente acerca de qualquer tema e, muitas vezes, faz com que o falante esteja supostamente legitimado a utilizar palavras que, diretamente ou não, expressem o seu ódio em relação a determinadas pessoas ou grupos minoritários que possuem certas características tidas como diferentes.

Logo, o termo hate speech está ligado ao incitamento ao ódio através do discurso ou do emprego de expressões que abordem clara e negativamente assuntos como religião, orientação sexual, etnia, entre outros. Ressalte-se que tal situação pode acontecer, inclusive, através das mídias digitais, o que merece especial atenção, mormente no que toca aos valores adotados pelo texto constitucional. Consoante salienta Sarmento:

\begin{abstract}
A análise desta questão transcende a simples interpretação do texto constitucional, envolvendo, necessariamente, o manejo de diversos valores extremamente importantes numa sociedade democrática, como liberdade, igualdade e tolerância, que, como não poderia deixar de ser, abrem-se a leituras muito divergentes. ${ }^{11}$
\end{abstract}

A Declaração Universal dos Direitos Humanos, em seu artigo 19, declara textualmente que "toda pessoa tem direito a liberdade de opinião e expressão; este direito inclui a liberdade de ter opiniões e de procurar, receber e transmitir informações e ideias por quaisquer meios e independentemente de fronteiras" ${ }^{12}$.

\footnotetext{
${ }^{10}$ TRAVASSOS, Marcela Maffei Quadra. Mídia Hate speech e liberdade de expressão. In: SCHREIBER, Anderson. (coord.), Direito e Mídia. Atlas, 2013, p. 291.

${ }^{11}$ SARMENTO, Daniel. A ponderação de interesses na Constituição Federal. Rio de Janeiro: Lumen Juris, 2000, p. 06.

${ }_{12}$ ORGANIZAÇÃO DAS NAÇÕES UNIDAS. Declaração Universal dos Direitos Humanos. Nova York: Assembleia Geral das Nações Unidas, 1948. In: Declaração Universal dos Direitos Humanos. São Paulo: Acervo da Biblioteca Virtual de Direitos Humanos da
} 
Observa-se que a liberdade de expressão se liga essencialmente à liberdade de comunicação de pensamentos, ideias e opiniões, constituindo garantia dirigida a todas as pessoas como um direito da humanidade; assim sendo, tem-se a liberdade de expressão como um autêntico direito humano.

Contudo, é necessário registrar que a liberdade de expressão como direito e garantia fundamental também encontra limitações constitucionais, tais como a vedação do anonimato, o direito de resposta e o dever de reparação de eventuais danos.

Retomando a ideia do Estado garantidor do livre exercício da referida liberdade, surge o desafio de promover o equilíbrio no espaço do discurso. Preleciona Peterke que:

[...] a obrigação de respeitar um determinado direito humano não significa que qualquer interferência estatal resulta necessariamente em sua violação. Pelo contrário, o teor dos diversos direitos humanos prevê expressis verbis a possibilidade de restringi-los sob certas condições, assim justificando a adoção de uma série de medidas pelo Estado. Por exemplo, a liberdade de expressão, garantida pelo art. 19 do PIDCP, [...] poderá ser sujeita a certas restrições, que devem, entretanto, ser expressamente previstas em lei e que se façam necessárias para assegurar o respeito dos direitos e da reputação das demais pessoas $[\ldots] .^{13}$

No Brasil, por exemplo, o acesso diferenciado aos meios de comunicação de massa, alcançado por determinados grupos, a

\footnotetext{
USP, $2016 . \quad$ Disponível em: <http://www.ohchr.org/EN/UDHR/Documents/UDHR_Tr anslations/por.pdf >. Acesso em: 05 fev. 2016.

${ }^{13}$ PETERKE, Sven. Os direitos humanos internacionais como direitos objetivos e subjetivos. In: PETERKE, Sven (Coord.). Manual prático de direitos humanos internacionais. Brasília: Escola Superior do Ministério Público da União, 2009, p. 156.
}

pressão ou influência exercidas pelo governo sobre as empresas de comunicação, e, especialmente, preconceitos difundidos na sociedade contra determinados grupos sociais (ordinariamente minoritários) geram um latente desequilíbrio de forças.

As manifestações coléricas e odiosas tendem a encontrar suposto respaldo no exercício legítimo da liberdade de expressão. E, assim, a violência parece ser legitimada e ganha cada vez mais espaço, tanto na vida cotidiana quanto na cobertura midiática.

Desconsidera-se, com essas práticas, também ser o pluralismo fundamento para refrear eventuais excessos na liberdade de expressão. Tal pluralismo detém peso decisivo na conformação e assimilação de uma sociedade diversificada, que necessita de condições paritárias para a construção do desenvolvimento do Estado e de cada um dos cidadãos.

Não se pode compreender uma sociedade tão diversa como a brasileira, com particularidades culturais e regionais, ser necessariamente obrigada a manter o mesmo padrão de atividades para o desenvolvimento de cada segmento social, mormente quando a discussão sobre direitos civis está afeta a um segmento específico contra quem a prática do hate speech frequentemente se dirige.

Aceitar a diversidade significa promover o enquadramento de cada um dos elementos socioculturais como fundamento $\mathrm{e}$ mecanismo de defesa dos interesses de todos os indivíduos, dando-lhes a oportunidade de lutar pelos seus direitos, sem o temor reverente da contrapartida de um discurso odioso contra si perpetrado.

Quanto ao aspecto da autonomia privada propriamente dita, que permite o amplo exercício do direito à livre expressão, tem-se que o Estado não deve autorizar a prática de atividades ou discursos que visem ao aniquilamento ou menoscabo de outros direitos 
ou liberdades. Eis que surge a tênue fronteira entre o exercício da liberdade de expressão e o seu abuso, tendente a abolir outros direitos e liberdades, ou, ainda, comprometer seu exercício.

Sobre o tema, Marmelstein aponta que:

Em diversas declarações de direitos pelo mundo afora, há a expressa menção ao princípio da proibição de abuso de direito fundamental. Em linhas gerais, esse princípio estabelece que nenhum direito fundamental deve ser interpretado no sentido de autorizar a prática de atividades que visem à destruição de outros direitos fundamentais. [...] Aqui no Brasil, não há uma norma constitucional expressa acolhendo o princípio da proibição de abuso de direito fundamental. Mas ele está latente no sistema constitucional brasileiro. ${ }^{14}$

O mesmo autor argumenta, ainda, que basta vislumbrar as inúmeras normas da própria Constituição Federal que possibilitam a limitação ou até mesmo a perda dos direitos fundamentais quando do abuso do seu exercício, a exemplo da inviolabilidade de domicílio, do sigilo das comunicações telefônicas e do próprio direito de reunião. Todos eles comportam exceções que nada mais são do que hipóteses em que ocorre o abuso em seu exercício. É o caso do flagrante delito, no que toca à tutela da inviolabilidade do domicílio; é o exemplo da investigação criminal, que excepciona o sigilo das comunicações; servem como ilustração, por fim, a necessidade de promoção dos fins pacíficos que autorizam o direito de reunião.

Visto sob outra ótica, o ordenamento jurídico brasileiro consagra o princípio da proibição ao abuso de direito fundamental, a partir de princípios e regras contidos na própria Constituição. Analisando-se a possibilidade de confronto na realização de dois direitos fundamentais, esbarramos em interessante

14 MARMELSTEIN, George. Curso de direitos fundamentais. 3. ed. São Paulo: Atlas, 2011, p. 459. questão que a doutrina brasileira já sistematizou com propriedade: a ponderação de interesses.

É a ponderação de interesses o quid norteador do sopesamento que solucionará o problema, sempre que, de um lado, houver o exercício de uma garantia constitucional como a liberdade de expressão e, de outro lado, um direito fundamental supostamente atacado ou violado pelo abuso em seu exercício.

A esse respeito, Sarmento explica:

A dignidade da pessoa humana afirma-se como o principal critério substantivo na direção da ponderação de interesses constitucionais. Ao deparar-se com uma colisão entre princípios constitucionais, tem o operador do direito de, observada a proporcionalidade, adotar a solução mais consentânea com os valores humanitários que este princípio promove. ${ }^{15}$

Para que se vislumbre solução adequada aos casos em que valores, bens e direitos (especialmente os direitos fundamentais, na formulação do Direito Público) venham a se confrontar, irrompe, como um componente do princípio geral de proporcionalidade, a técnica da ponderação. De acordo com ela,

uma restrição a um determinado direito fundamental é admitida quando endereçada à satisfação de outro direito individual ou bem coletivo constitucionalmente protegido, cujo peso ou importância revele-se igual ou superior, à luz das circunstâncias concretas envolvidas. $^{16}$

Constatado um conflito entre direitos fundamentais, cuja incidência possa conduzir a soluções díspares para um mesmo problema, o desfecho preferencial consistirá no respeito a ambos os valores em colisão,

\footnotetext{
${ }^{15}$ SARMENTO, Daniel. A ponderação de interesses na Constituição Federal. Rio de Janeiro: Lumen Juris, 2000, p. 74.

16 SOARES, Guilherme. Restrições aos direitos fundamentais: a ponderação é indispensável? In: Estudos em homenagem ao Prof. Doutor Joaquim Moreira da Silva Cunha. Coimbra: Ed. Coimbra, 2005, p. 332.
} 
permitindo-se atingir "uma harmonia ou concordância prática, isto em termos de cada um deles gozar de um igual espaço de operatividade". ${ }^{17}$ Não sendo viável conservar a convivência harmônica dos direitos em choque, caberá o apelo à sua hierarquização, dando-se prevalência ao valor que "se mostra mais próximo ou conforme à dignidade da pessoa humana, procurando ainda aqui, todavia, encontrar sempre um possível espaço de operatividade mínima ao valor subordinado". ${ }^{18}$

Em outras palavras, a lógica da ponderação sugere que, num primeiro momento, compete tentar conciliar os valores e interesses em causa, sem que nenhum deles tenha de ceder; se tal não for possível, cumprirá sopesá-los, segundo uma hierarquia que não pode deixar de considerar que:

a) qualquer solução, sobretudo em se tratando de direitos fundamentais e da personalidade, deve ser pautada pelo respeito à dignidade da pessoa humana parâmetro que se revela crucial para a resolução dos casos em que, por meio de discursos de ódio, a liberdade de expressão se mostra desmedida;

b) a escolha sobre qual dos valores deverá prevalecer será feita com base nas circunstâncias do caso concreto;

c) o emprego da ponderação concretiza uma noção de proporcionalidade. Para que se dê o afastamento (no todo ou em parte) da incidência de um direito em prol da eficácia de outro, é fundamental analisar se a importância da preservação do direito prevalecente é suficiente para justificar a restrição do direito sucumbente.

\footnotetext{
${ }^{17}$ Ibidem, p. 332.

${ }^{18}$ OTERO, Paulo. Disponibilidade do próprio corpo e dignidade da pessoa humana. In: CORDEIRO, António Menezes et al (org.). Estudos em honra do Professor Doutor José de Oliveira Ascensão, v. I. Coimbra: Almedina, 2008, p. 127.
}

A técnica da ponderação propõe, como medida inaugural, a incidência em conjunto de valores que, à partida, se revelam colidentes. $\mathrm{O}$ fato de tais valores se dirigirem a direções opostas não quer implicar, necessariamente, o completo afastamento de um e a absoluta prevalência do outro.

Se, todavia, a harmonização entre os valores conflitantes se mostrar impossível - o que poderá ocorrer em inúmeras circunstâncias que envolvam a liberdade de expressão em confronto com a tutela da dignidade humana e dos direitos da personalidade -, cumprirá contrapesá-los para verificar, na sua densificação, qual deles merecerá resguardo. Ainda que esta seja a solução a adotar, entretanto, a melhor saída implicará uma tentativa de não se sacrificar por completo o valor sucumbente, a não ser que a sua anulação seja necessária para a preservação do valor ao qual se conferirá primazia.

De toda forma, o comprometimento da liberdade de expressão se queda inevitável ante o abuso no exercício do direito fundamental à liberdade de expressão, especialmente no tocante ao reconhecimento da necessidade de preservação do núcleo duro da dignidade da pessoa humana e da manutenção de outros direitos fundamentais, como a honra, a imagem, a privacidade e a intimidade, entre outros valores que compõem a essência da personalidade dos seres humanos.

\section{O CASO DA JORNALISTA MARIA JÚLIA COUTINHO}

A mídia se caracteriza como o conjunto de meios de comunicação, tais como jornais, emissoras de rádio, cinema e internet, a partir do qual a sociedade se manifesta e expressa suas opiniões; assim, os discursos são produzidos pela coletividade a partir de determinado contexto social e divulgados na mídia, que atua como 
ferramenta que potencializará seus efeitos.

Castells ${ }^{19}$ alega que a Era da Informação representa o desencadeamento de uma capacidade produtiva jamais vista, mediante o poder da mente. A famosa frase citada pelo filósofo francês René Descartes, "penso, logo existo", poderia ser facilmente readaptada na atualidade enquanto "posto, logo existo". Os discursos publicados nas mídias digitais podem ser positivos, mas também extremamente marcados por ódio, preconceito e racismo, como o fato ocorrido com Maria Júlia Coutinho.

Em julho de 2015, a jornalista do Jornal Nacional, popularmente conhecida como Maju, teve sua imagem publicada na página do programa jornalístico no Facebook. Em seguida, observaram-se inúmeros comentários ofensivos, que acarretaram enorme repercussão.

Não há qualquer dificuldade para constatar que o conteúdo presente nos comentários proferidos na fanpage do Jornal Nacional corresponde à adoção de discursos de ódio, conforme ilustra Almeida:

Comunicação que não carrega nenhum outro significado além da expressão de ódio por algum grupo, especialmente em circunstâncias nas quais a comunicação é susceptível de provocar violência. É uma incitação ao ódio principalmente contra um grupo de pessoas definidas em termos de raça, etnia, nacionalidade, sexo, religião, orientação sexual, e similares. O discurso do ódio pode se dar em qualquer forma de expressão considerada ofensiva para os grupos raciais, étnicos e religiosos e outras minorias discretas ou para as mulheres. ${ }^{20}$

Nas redes sociais, prevalece a sensação de anonimato, estimulada pela criação de perfis virtuais falsos (denominados fake), em que

${ }^{19}$ CASTELLS, Manuel. A era da informação: economia, sociedade e cultura. São Paulo: Paz e Terra, 1999, p. 437.

${ }^{20}$ ALMEIDA, Rafael Luft de. A liberdade de Expressão e o Discurso de Ódio na Era da Internet. Revista de Direitos das novas tecnologias, São Paulo, n.8, jul/2011-jun/2012, p. 16. indivíduos podem expressar, à partida, sem ser reconhecidos. Foi justamente por meio das contas eletrônicas falsas, algumas desativadas após o incidente, que provieram vários comentários discriminatórios, acarretando dificuldade para a localização de seus verdadeiros mentores.

O Ministério Público de São Paulo comandou uma operação em oito estados (Amazonas, Ceará, Goiás, Minas Gerais, Pernambuco, Rio Grande do Sul, Santa Catarina e São Paulo), com a finalidade de recolher provas por crimes de racismo contra a jornalista Maria Júlia Coutinho.

A internet inova ao propor uma quebra da tradicional na produção de informações por parte da televisão, jornal e revista; a partir da propagação das informações nas redes, as pessoas não apenas recebem a notícia enquanto sujeitos passivos da informação, mas também poderão ativamente produzi-la. Nesse entendimento, Lévy ${ }^{21}$ defende que os destinos da democracia e do ciberespaço estão amplamente ligados, pois este é o locus de livre e transparente manifestação, sem impedimentos prévios, não mais havendo hierarquia entre quem produz a informação e quem apenas a recebe.

No entanto, percebe-se que, no mais das vezes, não há limites aparentes nas informações veiculadas nas redes sociais, o que frequentemente ocasiona os discursos de ódio. Destarte, torna-se fundamental incentivar a criação de leis específicas e dispositivos que atinjam condutas consideradas abusivas, nomeadamente o hate speech.

${ }^{21}$ LÉVY, Pierre. Ciberdemocracia. Lisboa: Editions Odile Jacob, 2002, p. 32. 
4 O PROBLEMA DAS REDES SOCIAIS ENQUANTO DIFUSORAS DO HATE SPEECH

É evidente a conotação do texto constitucional e da doutrina pela escolha de possíveis limitações à livre expressão, quando esta estiver em confronto com outros valores ou direitos que, na situação fática, digam respeito à tutela da dignidade humana, através do exercício da ponderação de interesses. Contudo, relevo maior se afere quando os direitos, especialmente os da personalidade, como a honra, imagem e privacidade, são violados nas mídias digitais, especialmente através da internet.

A comunicação social, prevista no Capítulo V do Título VIII (da ordem social) da Constituição Federal, explana a preocupação do constituinte com a promoção de uma sociedade democrática, de modo a proporcionar o debate e o diálogo entre os mais variados ideais existentes, sendo vedada toda e qualquer censura de natureza política, ideológica e artística, nos termos do $\S 2^{\circ}$ do art. 220.

Pela experiência vivida no país nos tempos de regime militar e da censura, revela-se a imprescindibilidade da liberdade de expressão e da liberdade de imprensa como consectários de desenvolvimento de um Estado Democrático. Contudo, o resguardo destas liberdades não significa a possibilidade de veiculação de manifestações de ódio, preconceito ou marginalização de pessoas ou grupos específicos.

Especialmente quando tal tipo de discurso é propagado por meio das redes sociais, ambiente em que inexiste pleno controle sobre o alcance e impacto do conteúdo disseminado, o registro odioso poderá promover danos em caráter permanente. $\mathrm{O}$ problema se verifica nos casos em que a identificação do hate speech normalmente não se encontra de modo evidente no ambiente virtual, situações em que seus propagadores almejam implicitamente convocar e incentivar seus seguidores.

Ao deparar-se com uma situação de violação de direito, nem sempre são eficazes os instrumentos normativos de contenção ou reparação de danos. Neste contexto, em particular, emerge a relevância dos preceitos contidos no Marco Civil da Internet (Lei n. 12.965/2014), que, ao mesmo tempo em que consagra a liberdade de expressão enquanto fundamento da disciplina do uso da internet no Brasil, resguarda, por igual, valores como a pluralidade, a diversidade e os direitos humanos, o desenvolvimento da personalidade e o exercício da cidadania em meios digitais (vide incisos II e III, em especial, do art. $2^{\circ}$ ). Outras regras dignas de nota, contidas no Marco Civil da Internet, permitem a identificação de usuários das redes que cometam atos infracionais e a eventual responsabilização não apenas do responsável direto pelo cometimento de atos ilícitos, como também dos próprios provedores de internet. Tais avanços, embora notáveis, ainda não permitem inferir que tenha ocorrido a mitigação dos discursos de ódio perpetrados na internet.

Decorre então a importância da aplicação direta das normas constitucionais que garantem o exercício e a proteção não só dos direitos fundamentais, mas também dos direitos humanos, que devem ser entendidas como normas de eficácia plena, que prescindem de regulamentação. Malgrado as dificuldades, a compensação dos danos extrapatrimoniais tem se mostrado a melhor alternativa de reparação em tais casos, solução que nem sempre se mostra perfeita, já que fica a cargo da subjetividade do julgador e não impede a disseminação dos discursos de ódio.

\section{CONCLUSÃO}

Apesar de a liberdade de expressão ser tutelada como um direito fundamental, não pode 
ser considerada como um direito absoluto, intransponível. Nos casos em que a liberdade à manifestação do pensamento colidir com outros direitos fundamentais e/ou da personalidade, deve predominar aquele que represente de maneira mais eficaz a efetivação da proteção do sujeito e de sua eminente dignidade.

Para tanto, como método de solução dos confrontos entre direitos da personalidade ou fundamentais e princípios constitucionais, a aplicação do princípio da proporcionalidade e da técnica da ponderação tem se mostrado essencial, já que, a partir da análise das especificidades da situação, permite inferir qual direito melhor expõe o resguardo da dignidade da pessoa humana de forma integral.

A liberdade de expressão pode ser utilizada, à partida, como justificativa para manifestar pensamentos discriminatórios que desqualifiquem certas pessoas e/ou grupos em virtude de características determinadas, embasando, assim, o hate speech. Todavia, em se tratando do império da dignidade humana e da ampla tutela dos direitos da personalidade, cede a liberdade de expressão, sempre que se revelar abusivamente exercida.

Deve-se verificar os limites da liberdade de expressão, bem como a partir de que momento se inicia uma prática discursiva discriminatória, capaz não apenas de demonstrar o pensamento odioso, mas de gerar efeitos concretos nos grupos sociais estigmatizados, principalmente quando tais pensamentos são expressos na mídia digital.

Mais do que simples liberdade de expressão, o hate speech objetiva impor $\mathrm{e}$ espalhar condutas anti-igualitárias, como também cercear a diversidade, por meio da disseminação da intolerância e do ódio, violando-se, assim, a dignidade humana e, consequentemente, gerando um conflito entre esta e o direito fundamental à livre expressão do pensamento. Por meio do hate speech, se perpetua a prevalência não somente da aversão ao grupo estigmatizado, como também a permanência de relações de poder hierarquicamente formadas.

Caso se verifique, enfim, que a conduta teoricamente se embasa na liberdade de expressão, deve-se confrontá-la com a dignidade dos ofendidos, para que, tecnicamente e mediante os ideários de justiça do Estado Democrático de Direito, seja possível concluir qual das duas deve prevalecer, além de se estabelecer a devida reparação de danos e a imposição das correspondentes sanções criminais aos infratores.

\section{REFERÊNCIAS}

ALMEIDA, Rafael Luft de. A liberdade de Expressão e o Discurso de Ódio na Era da Internet. Revista de Direitos das novas tecnologias, São Paulo, n.8, jul/2011-jun/2012. p. 16.

ALEXY, Robert. Teoria de los derechos fundamentales. Madrid: Centro de Estudios Políticos y Constitucionales, 2002.

ANDORNO, Roberto. "Liberdade" e "dignidade" da pessoa: dois paradigmas opostos ou complementares na bioética? In: MARTINS-COSTA, Judith; MÖLLER, Letícia Ludwig (Org.). Bioética e responsabilidade. Rio de Janeiro: Forense, 2009, p. 73-93.

BRASIL. Constituição (1988). Constituição da República Federativa do Brasil. Brasília, DF: Senado Federal: Centro Gráfico, 1988. 
BRASIL. Pesquisa IBOPE: brasileiros passam uma média de 5,3 horas diárias na frente do computador pessoal. Disponível em: <http://www.dell.com/learn/br/pt/brcorp1/press-releases/201507-23-research-ibope>. Acesso em: 26 fev. 2016.

BRASIL. Presidência da República. Secretaria de Comunicação Social. Pesquisa brasileira de mídia 2015: hábitos de consumo de mídia pela população brasileira. Brasília: Secom, 2014.

CANOTILHO, José Joaquim Gomes; MOREIRA, Vital. Constituição da República Portuguesa anotada. 4. ed. Coimbra: Ed. Coimbra, 2007.

CASTELLS, Manuel. A era da informação: economia, sociedade e cultura. São Paulo: Paz e Terra, 1999.

COSTA, Ana Paula Correia de Albuquerque da; FERREIRA, Priscila; SOUZA, Clarissa Gomes de. Direitos Humanos na seara jusprivatística: a tutela da personalidade. In: GODINHO, Adriano Marteleto; COSTA, Ana Paula Correia de Albuquerque da; FEITOSA, Maria Luiza Pereira de Alencar Mayer (org.), Humanização Do Direito Civil-Constitucional: Perspectivas E Desafios. Florianópolis, Conceito, 2014.

DÍEZ-PICAZO, Luis Maria. Sistema de derechos fundamentales. Madrid: Thomson-Civitas, 2003.

FARIAS, Cristiano Chaves de; ROSENVALD, Nelson. Direito civil: teoria geral. Rio de Janeiro: Lumen Juris, 2008.

LÉVY, Pierre. Cibercultura. Tradução de Carlos Irineu Costa. São Paulo: Ed. 34, 1999.

LÉVY, Pierre. Ciberdemocracia. Lisboa: Editions Odile Jacob, 2002.

MACHADO, Jónatas. E. M. Liberdade de expressão: dimensões constitucionais da esfera pública no sistema social. Coimbra: Coimbra Editora, 2002.

MARMELSTEIN, George. Curso de direitos fundamentais. 3. ed. São Paulo: Atlas, 2011.

MIRANDA, Jorge. A dignidade da pessoa humana e a unidade valorativa do sistema de direitos fundamentais. In: Estudos em homenagem ao Prof. Doutor Martim de Albuquerque, v. I. Coimbra: Ed. Coimbra, 2010.

NOVAIS, Jorge Reis. Os princípios constitucionais estruturantes da República Portuguesa. Coimbra: Ed. Coimbra, 2004.

ORTIZ-ORTIZ, Rafael. La dignidad humana y el desarrollo de la personalidad como premisa axiológica del constitucionalismo venezolano. Revista de la Fundación Procuradoria, Caracas, a. 11, n. 14 (1996), p. 15-297.

OTERO, Paulo. Disponibilidade do próprio corpo e dignidade da pessoa humana. In: CORDEIRO, António Menezes et al (org.). Estudos em honra do Professor Doutor José de Oliveira Ascensão, v. I. Coimbra: Almedina, 2008, p. 107-138. 
Recebido em: 08/07/2018 Aceito em: 07/11/2018 
